\title{
ESTUDO COMPARATIVO DO DESEMPENHO DE MINIRREGISTRADORES DIGITAIS DE TEMPERATURA E UMIDADE DO AR EM ABRIGO METEOROLÓGICO PADRÃO E NO MINIABRIGO METEOROLÓGICO ASPIRADO
}

\author{
Tarik Rezende de Azevedo* \\ José Roberto Tarifa* *
}

\section{Introdução}

O trabalho de campo em climatologia, no âmbito da geografia, muitas vezes demanda a observaçāo e registro instrumental de atributos atmosféricos desde algumas horas até semanas e, eventualmente, meses. Além disso, muitas vezes é necessária, ou desejável, uma rede amostral densa. O custo elevado dos instrumentos registradores autônomos e a dificuldade de alocar pessoal para observação simultânea normalmente constituem os fatores limitantes da investigaçāo mais acurada do clima, sobretudo com grande detalhamento espacial e temporal (TARIFA, 1976).

AZEVEDO e FUNARI (2001) avaliam o desempenho de dois minirregistradores (umidade relativa e temperatura do ar) de baixo custo, sob as condiçōes ambientes no interior do abrigo meteorológico padrāo, e concluem que os registros produzidos pelos mesmos nāo são comparáveis, sem correçōes, com os registros produzidos a partir dos instrumentos analógicos convencionais. Sugerem também que o campo de radiação termal influencia o desempenho dos minirregistradores testados de forma mais intensa que dos instrumentos convencionais.

AZEVEDO e TARIFA (2001) apresentam um Miniabrigo Meteorológico Aspirado (MMA), desenvolvido no Laboratório de Climatologia e Biogeografia (LCB) da Universidade de São Paulo, com uma soluçāo de baixo custo que permite o registro contínuo da temperatura e umidade relativa do ar. O MMA é quase estanque à luz e possui paredes que proporcionam isolamento térmico mais eficiente que a madeira. Por outro lado, o restrito volume interno, aliado à aspiração contínua do ar, proporciona um ambiente que, em tese, deveria responder mais fidedignamente às variaçōes da temperatura e umidade do ar isolando-as das variaçōes do campo de radiaçāo visível e termal. Como vantagem adicional, o fluxo de ar contínuo eliminaria a interferência direta das variações na intensidade e direçāo do vento no desempenho dos instrumentos.

\footnotetext{
*Geógrafo, Professor do Departamento de Geografia da Faculdade de Filosofia, Letras e Ciéncias Humanas da Universidade de São Paulo e Colaborador do Laboratório de Climatologia e Biogeografia. xtarikx@usp.br

* Geógrafo, Professor do Departamento de Geografia da Faculdade de Filosofia, Letras e Ciéncias Humanas da Universidade de Sào Paulo e Coordenador do Laboratório de Climatologia e Biogeografia.
} 
Neste trabalho é feita uma avaliaçāo do desempenho do Miniabrigo Meteorológico Aspirado (MMA) do LCB em condiçōes reais de uso, comparando com registros produzidos simultaneamente nas mesmas condiçōes de AZEVEDO e FUNARI (op cit). O objetivo é testar se o registro de temperatura e umidade produzido por minirregistradores no MMA é mais confiável que o produzido no interior do abrigo meteorológico padrão.

\section{Instrumental empregado e procedimentos adotados}

Os registros simultâneos usados neste trabalho abrangem de 0 h00 de 11 de julho de 2000 às 24 hoo de 15 de agosto de 2000 .

O MMA foi instalado no poste de iluminaçāo do cercado meteorológico da Estaçāo Meteorológica da Água Funda (EAF) do Instituto Astronômico e Geofísico da Universidade de Sāo Paulo, com a abertura de entrada do ar a $2 \mathrm{~m}$ da superfície do solo ${ }^{1} \mathrm{Em}$ seu interior, foram instalados os mesmos minirregistradores digitais usados por AZEVEDO e FUNARI (op cit):

a) A temperatura registrada a cada meia hora pelo termómetro minirregistrador digital $^{2}$ (TMD 1) é a temperatura do minirregistrador digital no MMA (T1);

b) A umidade relativa registrada a cada meia hora pelo higrômetro minirregistrador digital ${ }^{3}$ (HMDl) é a umidade relativa do minirregistrador digital no MMA (UR 1).

No interior do abrigo meteorológico padronizado, segundo as normas da OMM, da Estação Meteorológica da Água Funda pertencente ao Instituto Astronômico e Geofísico (IAG) da Universidade de Sāo Paulo, localizada no Parque das Fontes do Ipiranga, Município de São Paulo, permaneceram simultaneamente os outros dois minirregistradores digitais empregados:

c) A temperatura do ar obtida pelo TMD2 $^{4}$, similar ao TMD1, é a temperatura do minirregistrador digital no abrigo meteorológico padrāo (T2). d) A umidade relativa do ar registrada pelo HMD2 ${ }^{5}$, similar ao HMD1, é a umidade do minirregistrador digital no abrigo meteorológico padrão (UR2).

Adotou-se a temperatura horária do ar, divulgada pela Estaçāo Meteorológica da Água Funda, como a temperatura padrão do ar (TP). A Tp é obtida em intervalos de 1 hora, das 07 h00 à meia-noite (horário local) por meio do psicrômetro de aspiraçāo de Assmann ${ }^{6}$ A Tp dos seis horários entre 1 hoo e 6 h00 é obtida por interpolação, a partir da leitura dos diagramas diários do termógrafo ${ }^{7}$ distribuindo linearmente a diferença entre esta e Tp à meia-noite e às 07 h00, procedimento adotado mundialmente.

A umidade relativa do ar horária, divulgada pela Estação Meteorológica da Água Funda, é considerada, neste trabalho, a umidade relativa padrāo (URp). Do psicrômetro de aspiraçāo de Assmann, obtém-se simultaneamente à $\mathrm{Tp}, \mathrm{a}$ temperatura de bulbo úmido horária (Tu). URp é obtida a partir de Tp, Tu e da pressāo atmosférica reduzida a $0^{\circ} \mathrm{C}$, no período das 07 h00 à meia-noite. Nos seis horários intermediários, URP é obtida a partir da leitura direta do diagrama diário do higrógrafo de harpa de fio de cabelo ${ }^{8}$. segundo a mesma metodologia adotada para Tp (IAG, I999).

Preliminarmente, foi realizada a verificaçāo qualitativa da coerência entre os registros e o conjunto das observaçōes meteorológicas, procurando identificar discrepancias e possiveis falhas de notação ou transcrição, sem recorrer a métodos estatisticos.

Foram calculados os seguintes parâmetros estatisticos de cada série de registros obtidos:

a) minimo, máximo, amplitude, média aritmética simples, desvio médio, variancia, curtose e assimetria sem distinçōes horárias e diárias;

b) os mesmos paràmetros do item a, por horário do dia para cada série de registros e para as seguintes diferenças entre séries: T1-TP, T2-TP, T1-T2, UR1URP, UR2-URP, UR1-UR2; 
c) os mesmos parâmetros do item a, por dia para cada série de registros $e$ para as mesmas diferenças entre séries do item b.

d) os mesmos parâmetros do item a, para o gradiente horário em cada série.

Deve ser ressaltado que, nos casos b e c, a amostragem é muito menor que no caso a; 24 por dia ou 30 por hora para cada série de temperaturas, não permitindo a comparação segura dos parâmetros de simetria e dispersão, pois um único valor excepcional pode alterar significativamente os resultados, sobretudo se as variaçōes dentre os valores obtidos para cada paràmetro forem pequenas. Assim sendo, apesar de calculados, os parâmetros de simetria e dispersāo foram desprezados, evitando a construção de conclusōes pouco seguras. Priorizou-se a análise gráfica nesses dois casos.

Foram calculados: o coeficiente de correlaçāo linear, os parâmetros da reta de regressão linear e polinomial do segundo grau pelo método dos mínimos quadrados e o coeficiente de determinação para as seguintes relaçōes: $T l=f(T p)$, $T 2=f(T p), \quad T 1=f(T 2), \quad U R 1=f(U R p), \quad U R 2=f(U R P)$, $\mathrm{UR} \mathbf{l}=\mathrm{f}(\mathrm{UR} 2)$.

\section{Resultados}

Nos meses de inverno em Sāo Paulo, ocorre com maior freqüencia seqüencias de vários dias sob domínio progressivo de centros de alta pressão e, conseqüentemente, alta estabilidade atmosférica, baixa nebulosidade e precipitaçāo, entremeadas pela passagem da frente polar e a instabilidade que lhe é intrinseca. Nessas seqüencias de tipos de tempo, os instrumentos sāo submetidos a variaçōes extremas de temperatura e umidade em poucas horas, tornando o teste de seu desempenho viável com poucas semanas de registro.

O periodo selecionado de 37 dias foi particularmente propício à investigação proposta neste trabalho. Ocorreram situaçōes extremas de variação da temperatura e umidade relativa do ar em periodos de algumas horas. As trés únicas noites em que foram registradas geadas na EAF, no ano 2000, estão incluidas. Na madrugada do dia 16 para o dia 17 de julho, em que foi registrada, por um dos autores, forte geada também em Campos do Jordāo (SP), a temperatura mínima do ar chegou a $0,2^{\circ} \mathrm{C}$ e a umidade relativa do ar no início da tarde do dia 17 chegou a $28 \%$. Por outro lado, no dia 21 de julho registrou-se a maior amplitude térmica diária de 2000; $21,6^{\circ} \mathrm{C}$.

O total pluviométrico do período de 37 dias foi de $70,3 \mathrm{~mm}$ e a soma da média de julho e agosto de 1933 a 1999 na Estaçāo Meteorológica da Água Funda foi de apenas $78,6 \mathrm{~mm}$, sugerindo que, grosseiramente, teria chovido o dobro que a média. No entanto, a análise da seqüencia nos permite afirmar que a quase totalidade do total acumulado esteve diretamente associada a três passagens frontais, sendo as ocorrèncias menores apenas garoa e orvalho noturno (Figura 1). Por outro lado, longe do total de julho e agosto de 1976, extremo entre 1933 e 1999, 268,7 mm. De fato, sob este ponto de vista, deve ter sido um periodo com ritmo climático próximo do habitual.

A conferència e a análise qualitativa preliminar dos dados obtidos nāo identificou inconsistẽncias ou possiveis erros isolados nas séries de temperatura e umidade.

\subsection{Temperatura do ar}

A partir da tabela 1, na qual os dados das três séries foram agregados no periodo de 37 dias, depreende-se que a média de T1 é significativamente menor que a de Tp. A diferença $\mathrm{T} 2-\mathrm{TP}$ estaria situada no limite da precisāo instrumental, neste caso entre $0,1 \mathrm{e}$ $0,2^{\circ} \mathrm{C}$. Quando tomados os valores extremos de cada série, identifica-se que os extremos de T2 foram mais próximos de Tp que os extremos de T1. As maiores diferenças ocorreram entre os dois TMD. Esses elementos poderiam sugerir em uma análise simplista, que T2 represente melhor a temperatura do ar que $\mathrm{T} 1$. 


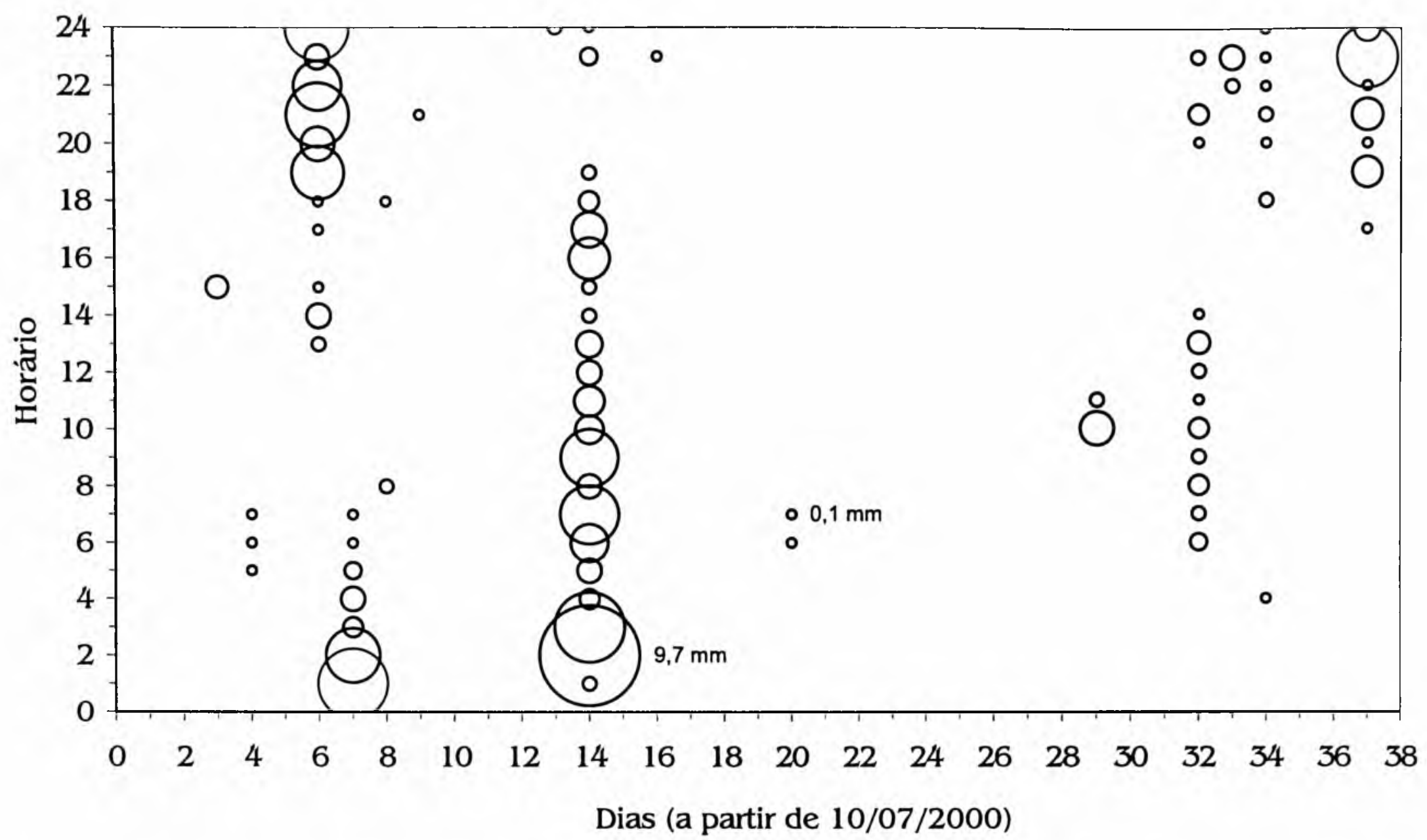

Figura 1: Precipitação horária $(\mathrm{mm} / \mathrm{h})$ na Estação Meteorológica da Água Funda - 10/07 a 15/ 08 de 2000.

Tabela 1: Parâmetros estatísticos da temperatura do ar

\begin{tabular}{|c|c|c|c|c|c|c|c|c|}
\hline \multirow[t]{2}{*}{ Hora } & \multicolumn{2}{|c|}{ T1 } & \multicolumn{2}{|c|}{ T2 } & $\mathbf{T p}$ & \multirow[t]{2}{*}{ T1-TP } & \multirow[t]{2}{*}{ T2-TP } & \multirow[t]{2}{*}{ T1-T2 } \\
\hline & (reg. & no MMA) & (reg. & abrigo padrão) & (temp padrão) & & & \\
\hline Menor & & 0,0 & & 0,6 & 1,3 & $-2,0$ & $-1,7$ & $-2,6$ \\
\hline Médio & & 13,5 & & 13,7 & 13,8 & $-0,3$ & $-0,1$ & $-0,2$ \\
\hline Maior & & 28,9 & & 29,5 & 29,5 & 1,5 & 2,5 & 1 \\
\hline Amplitude & & 28,9 & & 28,9 & 28,2 & 3,5 & 4,2 & 3,6 \\
\hline Variaçāo & & 24,63 & & 25,27 & 24,60 & 0,19 & 0,17 & 0,24 \\
\hline Desvio médio & & 3,74 & & 3,82 & 3,77 & 0,31 & 0,29 & 0,35 \\
\hline Curtose & & 0,62 & & 0,55 & 0,53 & 2,69 & 4,97 & 2,92 \\
\hline Assimetria & & 0,63 & & 0,62 & 0,64 & 0,08 & 1,27 & $-1,28$ \\
\hline
\end{tabular}


Por outro lado, a amplitude no periodo foi exatamente a mesma nos dois TMD, enquanto em $\mathrm{Tp}$ foi $0,7^{\circ} \mathrm{C}$ menor, repetindo, grosso modo, o resultado também obtido por AZEVEDO e FUNARI ( $O P$ cit). O desvio médio em relação à média é semelhante para Tl e Tp, mas significativamente maior para $\mathrm{T} 2$. As variâncias são significativamente distintas apenas entre T2 e as outras duas, resultando em uma seqüencia ordenada $\mathrm{T} 2>\mathrm{T} 1=\mathrm{Tp}$. Ou seja, globalmente, a dispersāo dos valores de Tl e Tp é semelhante na escala de temperatura usada, enquanto T2 é mais disperso. Considerando a curtose, obtémse um ordenamento diverso; $\mathrm{T} 1>\mathrm{T} 2>\mathrm{T}$ p, sugerindo que os valores sāo sucessivamente mais dispersos em torno do valor médio nesta mesma ordem. As três séries sāo consideravelmente assimétricas, fato conhecido e esperado para séries de temperatura. Do ordenamento da assimetria obtém-se que $\mathrm{T} p>\mathrm{T} 1>\mathrm{T} 2$, ou seja, a temperatura na altura máxima da curva de distribuição em relação ao valor médio é mais próxima de Tp no caso de Tl, embora a diferença entre os três valores seja muito pequena.

A análise das diferenças entre as leituras simultāneas permite distinguir que T1 e T2 apresentam atributos distintos. A amplitude de T1-Tp foi $0.7^{\circ} \mathrm{C}$ menor que a amplitude T2-Tp. A variāncia e desvio médio de T2-Tp foram menores que de T1-Tp, sugerindo que os valores sāo menos dispersos no primeiro caso, e considerando a curtose, mais concentrados em torno do valor médio. No entanto, a assimetria de T1Tp é praticamente nula, enquanto a assimetria de T2-Tp aponta para um desvio significativo maior que uma unidade de medida. Ou seja, globalmente, T2 apresenta um significativo desvio positivo em relaçāo à $\mathrm{T}$, enquanto $\mathrm{T} 1$ apresenta uma distribuição mais regular em relação à $\mathrm{Tp}$.

Na figura 2, está representada a média e extremos da diferença entre T1 e T2 simultâneas em funçāo do horário do dia. No periodo de $22 \mathrm{ho0}$ às $8 \mathrm{ho0}$, a pequena variação entre as médias de Tl-T2 ocorreu dentro da margem de precisāo instrumental, conforme destacado na própria figura 2 . No entanto, por volta das 10 h00 da manhã, a T2 tende a ser significativamente maior que T1. Entre 12 h00 e 13 hoo, a diferença tende novamente para a margem de precisào instrumental. Durante a tarde, a diferença tende a se acentuar até às $18 \mathrm{~h} 30$. Grosseiramente, os valores extremos acompanham esse comportamento. A análise gráfica de uma seqüencia de algumas horas (Figuras 3 e 4) permite identificar claramente que T2 apresentou desempenho e sugere inércia instrumental, sobretudo em relaçāo à Tl Esta, provavelmente induzida pelo fato do abrigo meteorológico depender de ventilação passiva, prejudicada quando submetido a periodos de calmaria ou

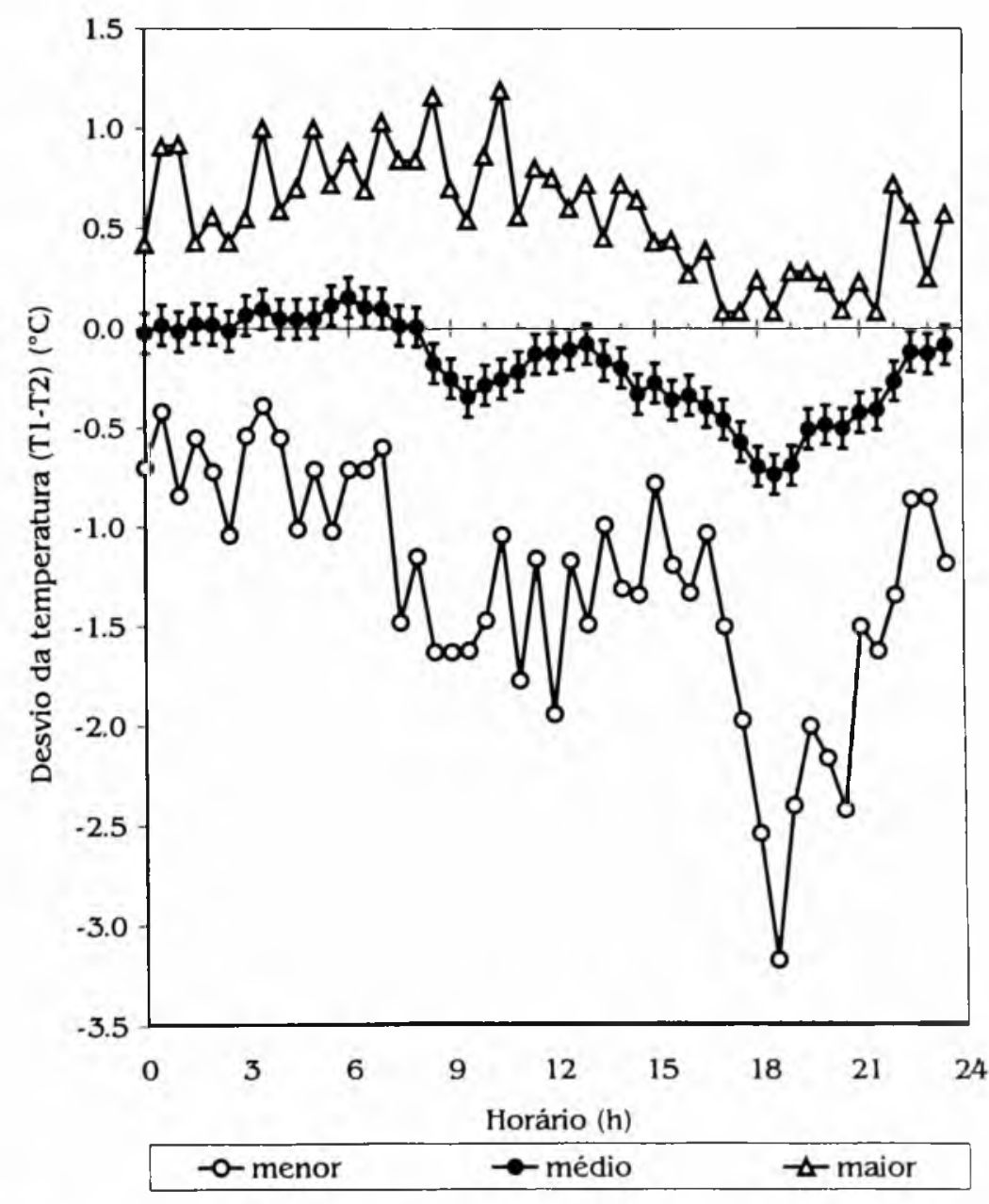

Figura 2: Desvio da temperatura do registrador do MMA em relação à temperatura do registrador no abrigo padrão (T1-T2) por horário. 


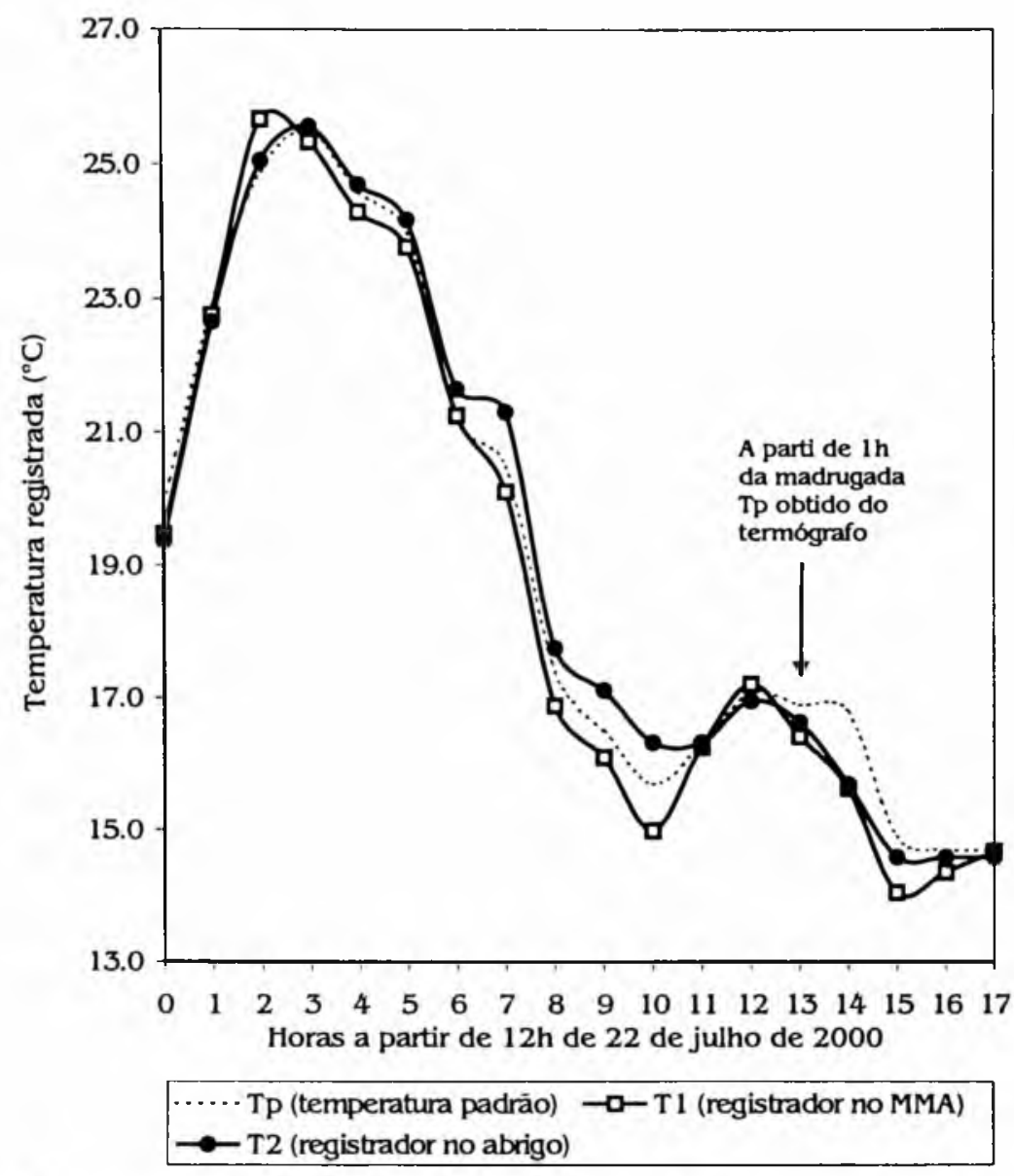

Figura 3: Exemplo ilustrativo do desempenho dos instrumentos - temperatura - 22 e 23 julho de 2000.

brisa muito fraca e pelo fato da radiaçāo termal e luminosa proveniente do solo penetrar o abrigo pelo estrado inferior, o que nāo ocorre no $M M A^{9}$ Esse efeito é maior no período da tarde de dias sob radiaçāo solar intensa, conforme pode ser constatado da análise das figuras $5 \mathrm{e}$ 6, que representam os desvios médios e extremos de $\mathrm{Tl}$ em relação às outras duas. $\mathrm{O}$ módulo dos desvios médios e extremos de T1 em relaçāo à T2 tende a ser maior, quāo maior for o fluxo diário de radiaçāo, o que nāo ocorre em relação à Tp. Ora, como o MMA foi concebido para minimizar deliberadamente o efeito da radiação sobre o sensor, deduz-se que é em T2 que a temperatura do ar tenha sido majorada, sobretudo pelo fato de que tanto $\mathrm{T} 1$ quanto Tp foram obtidos sob aspiraçāo durante o dia e início da noite; enquanto T2 nāo. Assim,

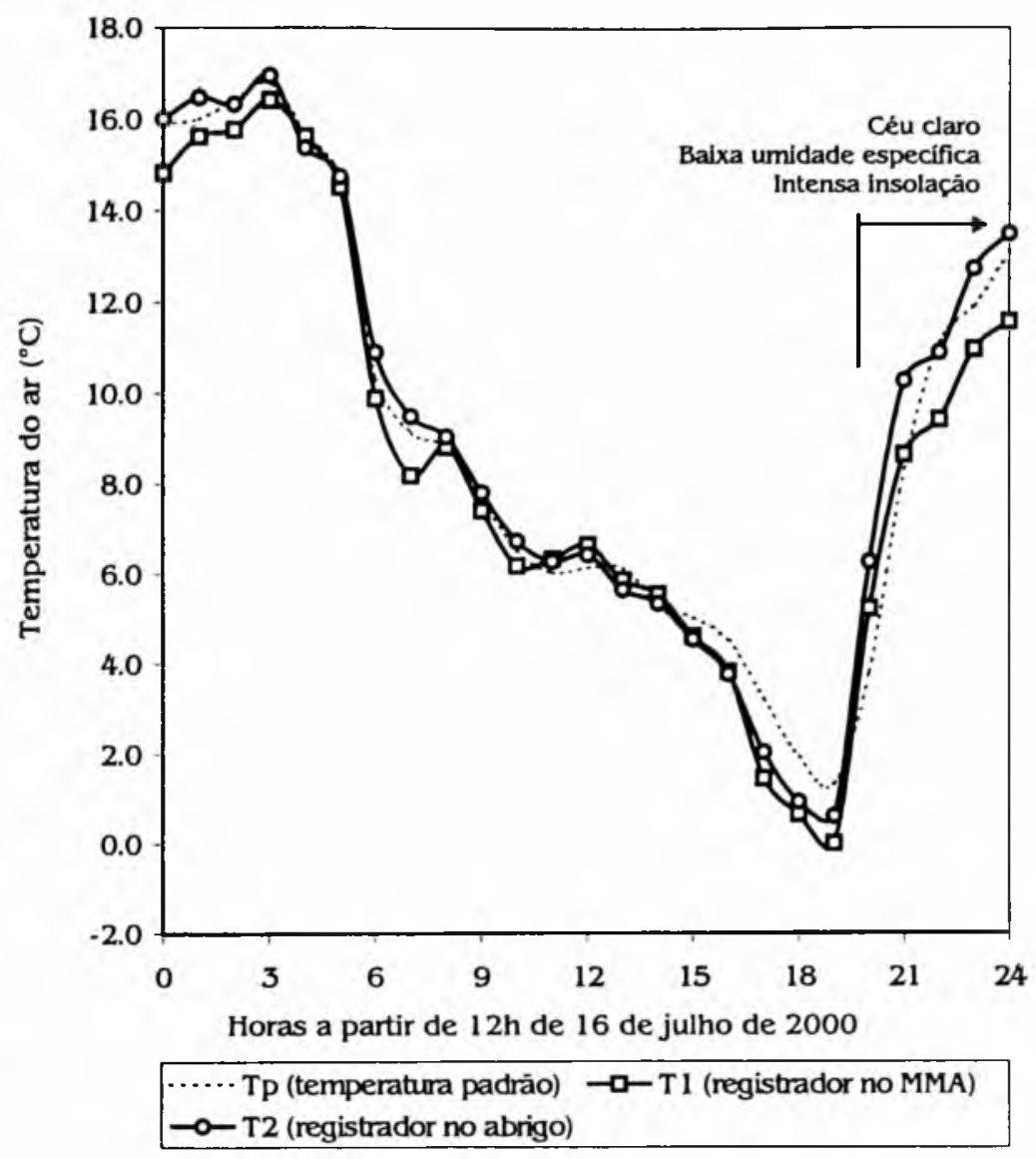

Figura 4: Exemplo ilustrativo do desempenho dos instrumentos - temperatura - 16 e 17 julho de 2000.

a tendència de T1-T2 se aproximar da precisão instrumental entre $12 \mathrm{hoO}$ e $13 \mathrm{hoO}$ (Figura 2) pode ser atribuida ao fato de que, nesse horário, a sombra do abrigo meteorológico incide no solo imediatamente abaixo do mesmo. Nos dias ensolarados, a temperatura de superficie do solo abaixo do abrigo deve cair sob a sombra, o que reduziria a radiaçāo emitida pela superficie do mesmo que entra no abrigo pelo estrado inferior.

A análise das figuras 7 e 8 permite evidenciar de forma qualitativa, mas veemente, o argumentado no parágrafo anterior. Observa-se na figura 8 que, recorrentemente no final da tarde e no início da noite, é que T2 apresenta valores maiores que Tl. Em alguns casos, a diferença chega a ser maior que $1^{\circ} \mathrm{C}$ durante quatro horas seguidas. Mas isto nāo ocorreu 


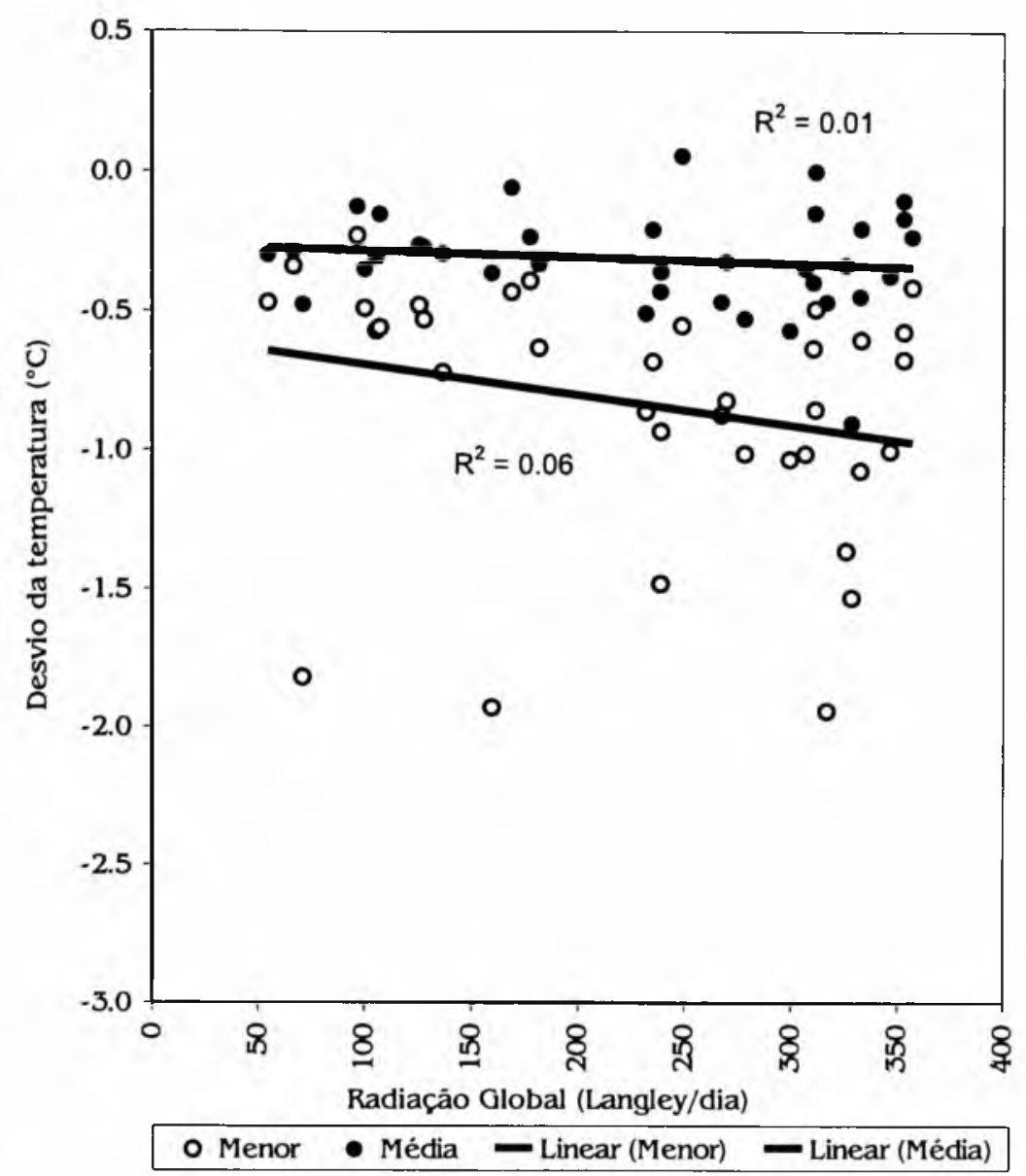

Figura 5: Desvio de $\mathrm{T} 1 \mathrm{em}$ relação à $\mathrm{Tp}$ de 12 às $18 \mathrm{~h} 00$ em função da radiação global no dia.

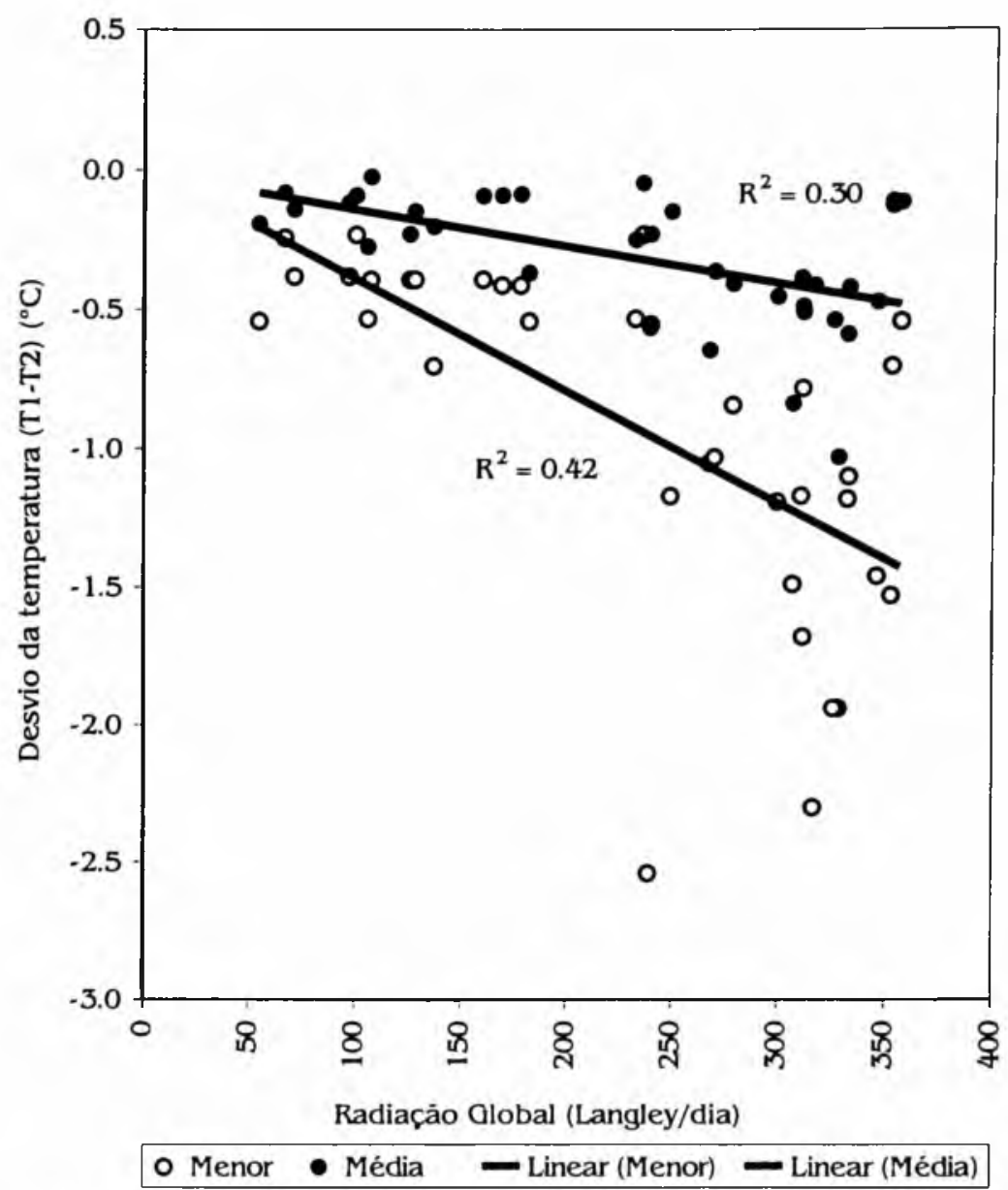

Figura 6: Desvio de $\mathrm{T} 1$ em relação à T2 de 12 às 18 h00 em função da radiação global no dia.

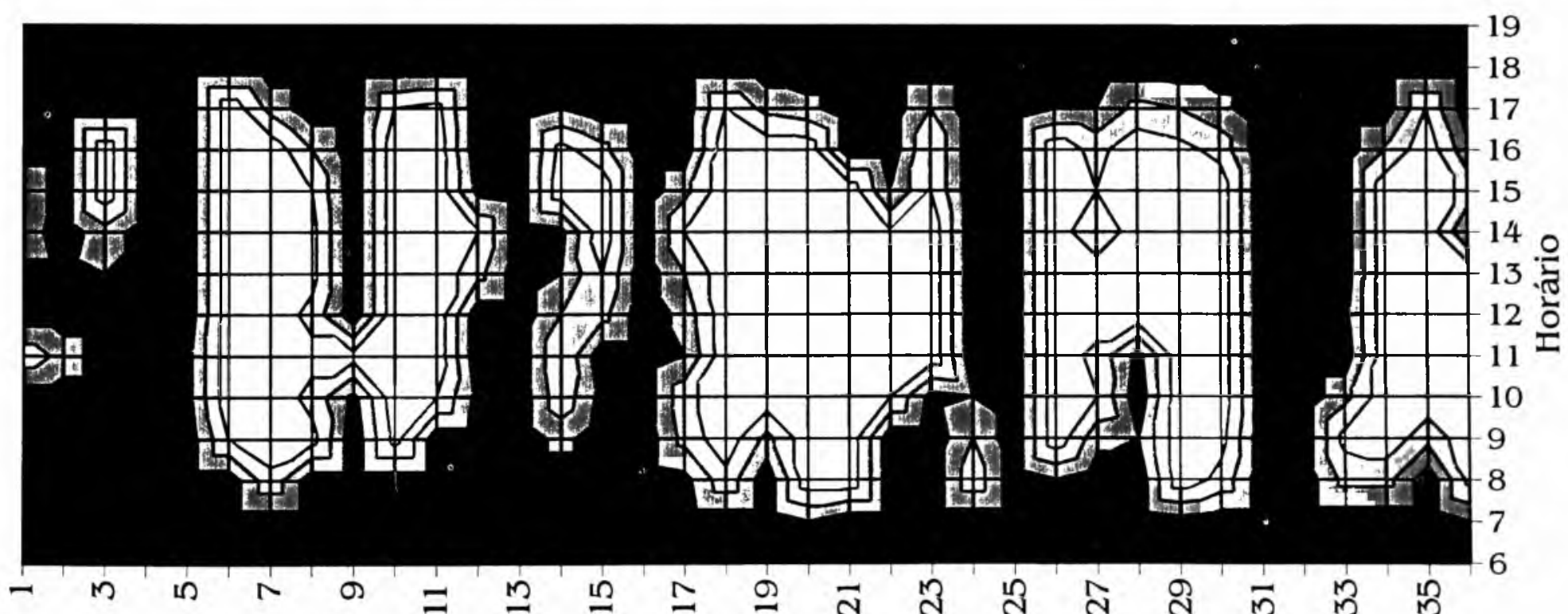

Dias a partir de 11 de julho de 2000

-0.1-0.2 圆0.2-0.5 $\square 0.5-0.8 \quad \square 0.8-1.1$

Figura 7: Insolação (horas de sol/h), Estação Meteorológica da Água Funda. 


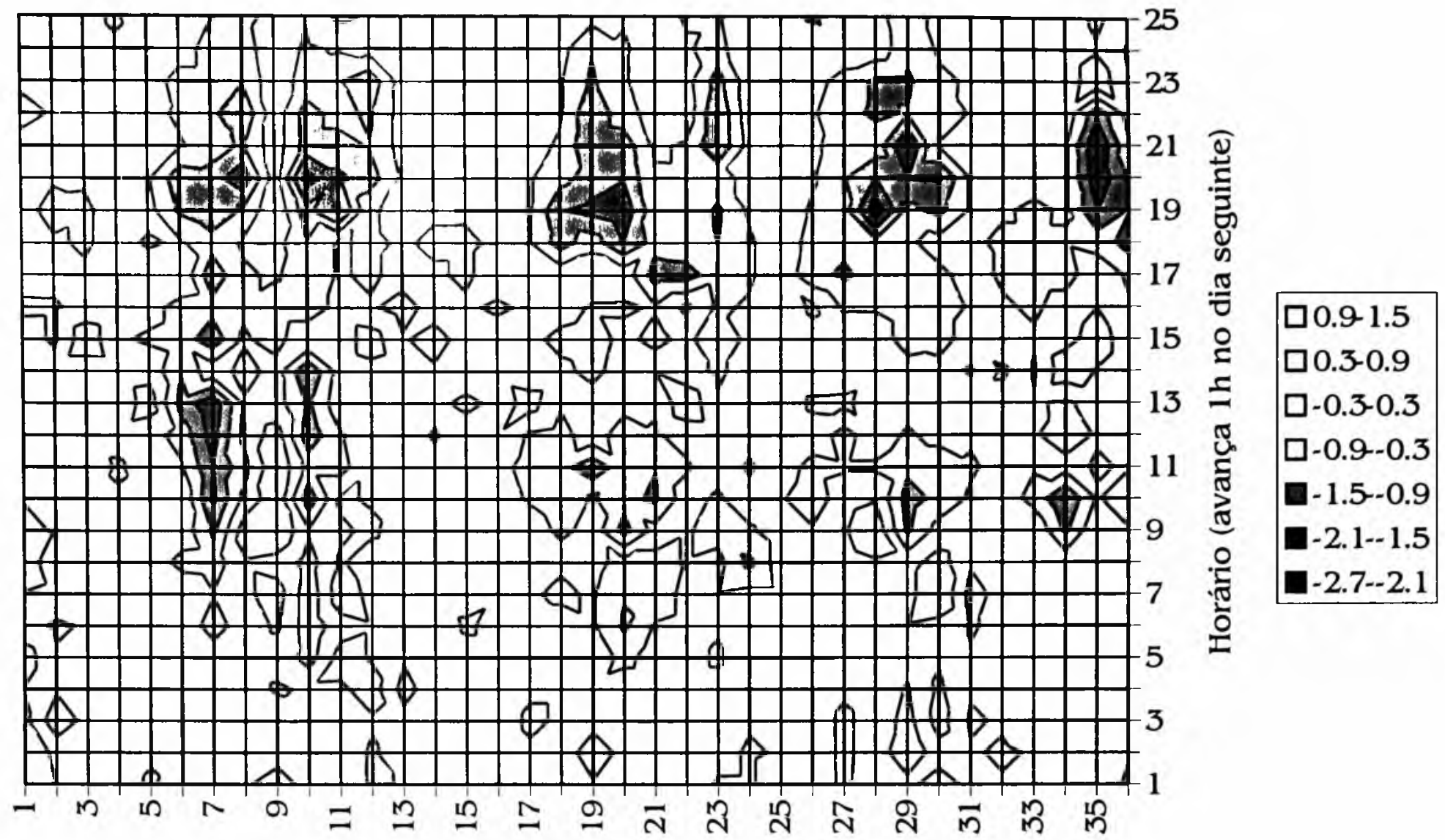

Dia a partir de 11 de julho de 2000

Figura 8: Desvio da temperatura do registrador no MMA em relação a do registrador no abrigo padrão $(\mathrm{T} 1-\mathrm{T} 2)\left({ }^{\circ} \mathrm{C}\right)$ por dia e horário.

todos os dias. Observando a figura 7 . constatase que todos os dias em que ocorreu, foram dias com pelo menos oito horas continuas de insolação maior que $0,8 \mathrm{~h} / \mathrm{h}$. Esses dias foram, todos dias sob média à forte subsidência sob dominio de alta pressāo, com baixa nebulosidade. Esse desvio da temperatura do minirregistrador em dias desse tipo também foi apontado por AZEVEDO e FUNARI ( $O P$ cit). Por outro lado, grosseiramente, nos dias "nublados" a diferença entre $\mathrm{T} 1$ e $\mathrm{T} 2$ raramente ultrapassa $0,3^{\circ} \mathrm{C}$.

Deve ser ressaltado também que Tp é obtido de 01 h00 às 06 hoo, a partir do registro do termógrafo analógico, dotado de alta inércia instrumental, conforme apontado por AZEVEDO e FUNARI ( $O P$ cit), fato conhecido na literatura meteorológica. Por outro lado, a análise da evo- luçāo da temperatura nos três instrumentos, durante a madrugada, no dia 17 de julho, evento extremo, sugere que o abrigo meteorológico e a campânula do termógrafo registrador interferem de forma sensivel no registro da temperatura noturna. T1, nesta madrugada em que houve forte geada, chegou a exatamente $0^{\circ} \mathrm{C}$, enquanto a minima registrada pelo termòmetro de minima de capilar com álcool registrou $-0,2^{\circ} \mathrm{C}$ pouco depois das 07 hoo da manhã. Nesta mesma madrugada, em Campos do Jordāo (SP), um dos autores registrou $-3.2^{\circ} \mathrm{C}$ para a temperatura do ar, o que sugere que as condiçōes meteorológicas em escala regional foram compativeis com o registro obtido no MMA. No entanto, da leitura do diagrama do termógrafo, mesmo depois de corrigida, não se obtém me- 
nos que $1,3^{\circ} \mathrm{C}$ nesta madrugada (Figura 3 ). Nesta noite, houve o congelamento da água na boca da torneira da cozinha da estação meteorológica, que, à espera de manutençāo, gotejava levemente, formando um longo "estalactite" Por outro lado, sobre o solo baixo do abrigo meteorológico nāo ocorreu a formação de geada, apenas em volta, o que sugere que o abrigo tenha formado um anteparo, reduzindo o fluxo radiativo proveniente do solo. Essa situaçāo extrema indica que esta interferència do abrigo, e da própria arquitetura do termógrafo se façam sentir também nas outras madrugadas, sendo a explicaçāo da ruptura na curva de Tp apontada na figura 3. Sendo assim, paradoxalmente, o registro da temperatura obtida no MMA talvez represente melhor a temperatura do ar durante a madrugada que Tp.

\subsection{Umidade relativa do ar}

No caso da umidade relativa do ar, a diferença de desempenho dos instrumentos foi muito mais sensivel que no caso da temperatura, de forma que a discussāo dos resultados pode ser abreviada. A comparação das figuras 9 e 10 permite distinguir claramente que URl apresentou-se muito menos disperso em relaçāo à URp que UR2. O que é reforçado pelo fato de que o coeficiente de determinaçāo para URl em função de URp é significativamente maior que para UR2. Podendo ser dito com segurança que, globalmente, UR 1 representa URp de forma consideravelmente mais confiável que UR2 (Tabela 2).

O exame da figura 11 , onde foram representadas as médias de UR 1 e UR2 por horário do dia, e da figura 12 onde foi representado

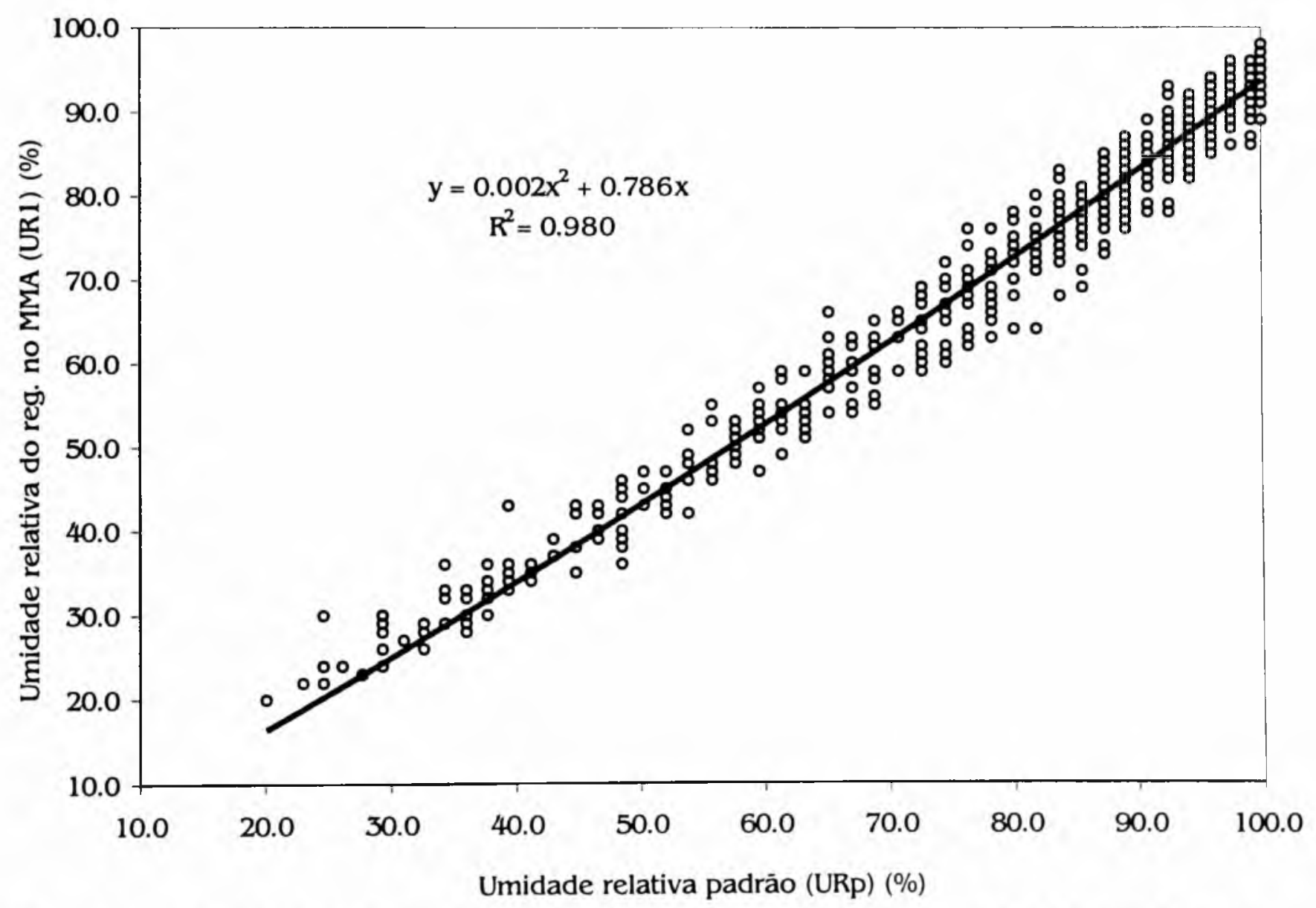

Figura 9: Umidade relativa do registrador no miniabrigo aspirado em função da umidade relativa padrão: $U R l=f(U R P)$. 
o desvio de URI em função de UR2, percebe-se claramente que UR2 tende a apresentar um "atraso" à variação da umidade relativa do ar. Esse efeito é quase imperceptivel no periodo da madrugada e passa a ser significativo por volta das $6 \mathrm{~h} 30$ da manhã. Até por volta das $14 \mathrm{~h} 30$, a tendência é de UR2 ser maior que URl e, a partir deste horário, a tendência se inverte. Isso pode ser atribuido ao fato de que UR l é obtido sob aspiração continua, forçando a película hidratar-se ou desidratar-se com maior velocidade que no caso de UR2 em que o sensor fica sujeito à ventilaçāo normal do abrigo. No entanto, deve haver um segundo fator agindo, pois há uma assimetria evidente entre o periodo em que o gradiente da umidade é negativo e aquele em que ele é positivo. Uma explicação plausivel é que o mesmo processo apontado para o caso da temperatura ocorra também para o caso da umidade relativa do ar. O calor irradiado do solo, abaixo do abrigo, força a temperatura para cima nos dias ensolarados, sobretudo nos final da tarde e início da noite. Tanto que o efeito é minimizado por volta das 22hoo. Da comparaçāo entre os gradientes horários médios de UR2 e Urp, em função do gradiente horário de URl (Figura 13), depreende-se que a relação entre os gradientes de URl e URp é significativamente maior que para os de UR2 e UR1.

A análise qualitativa da figura 14 permite verificar que os dias em que as diferenças entre UR 1 e UR2 foram maiores, foram os mesmos que no caso da temperatura, reforçando a argumentaçāo anterior.

\section{Conclusão}

As séries de temperatura e umidade relativa do ar, geradas pelo TMD e pelo UMD no MMA, são mais confiáveis que aquelas geradas pelos mesmos instrumentos no abrigo meteorológico padrāo, sobretudo no caso de valores extremos e de gradiente horário maior. No caso da umidade relativa do ar o ganho de desempenho é mais expressivo.

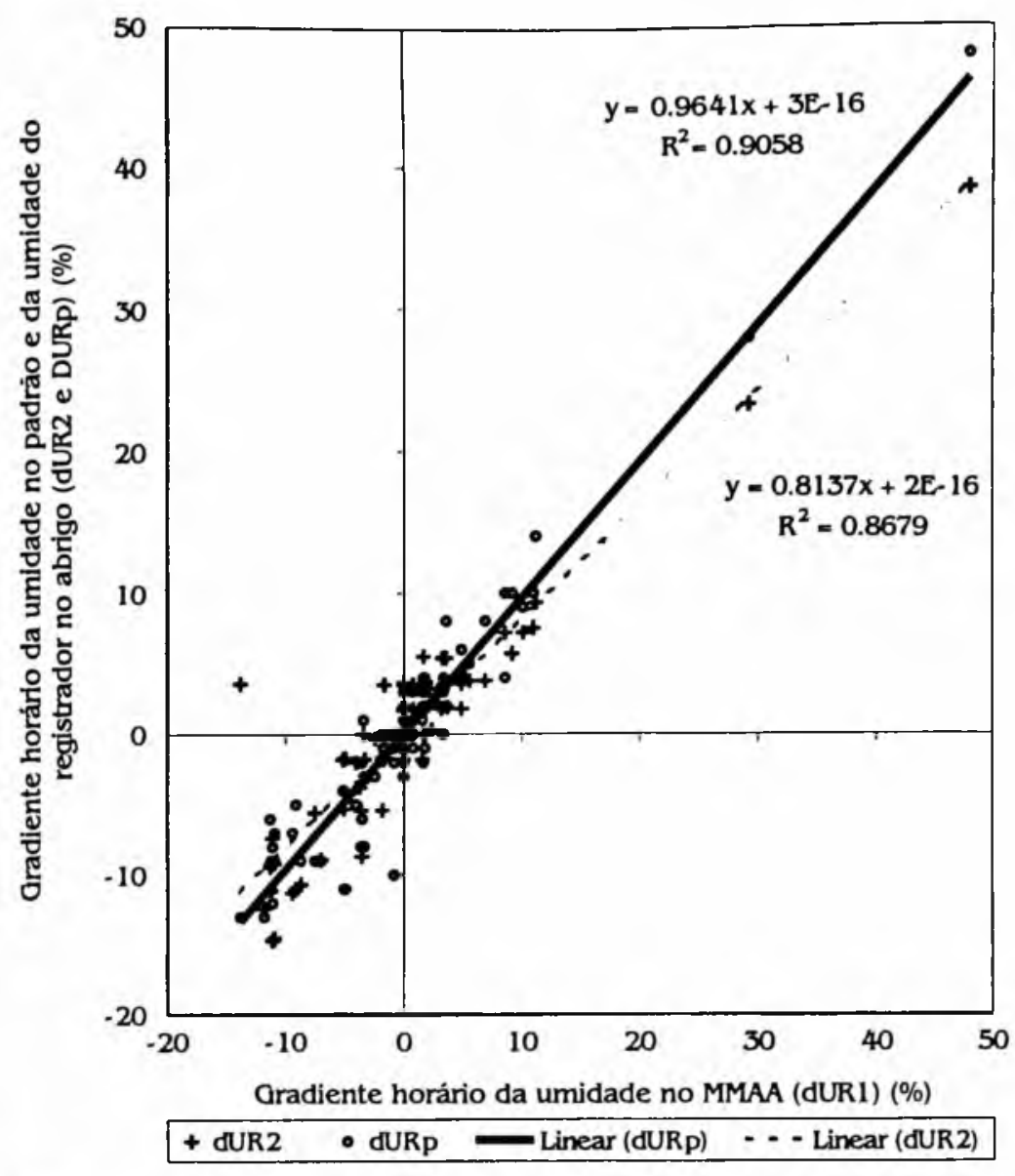

Figura 13: Desvio do gradiente horário de UR2 e URP em relação ao de UR1.

\section{Agradecimentos}

Ao Laboratório de Climatologia e Biogeografia do Departamento de Geografia da Universidade de Sāo Paulo, pela cessāo dos minirregistradores digitais.

Ao Instituto Astronômico e Geofísico pelos dados meteorológicos da Estaçāo Meteorológica da Água Funda e por abrigar e zelar pelos instrumentos do LCB no periodo desta pesquisa.

À FAPESP pelos recursos necessários à aquisiçāo dos minirregistradores digitais.

À CAPES pelo apoio financeiro para compra do material para confecçāo do MMA, através do PROAP.

A Frederico Luiz FUNARI, Sérgio SALUM e o Prof. Mário FESTA da Estaçāo Meteorológica da Água Funda, pelo apoio e revisāo minuciosa dos dados meteorológicos da mesma.

A Dra. Cristine Modenesi do Instituto Geológico pela leitura crítica deste texto. 


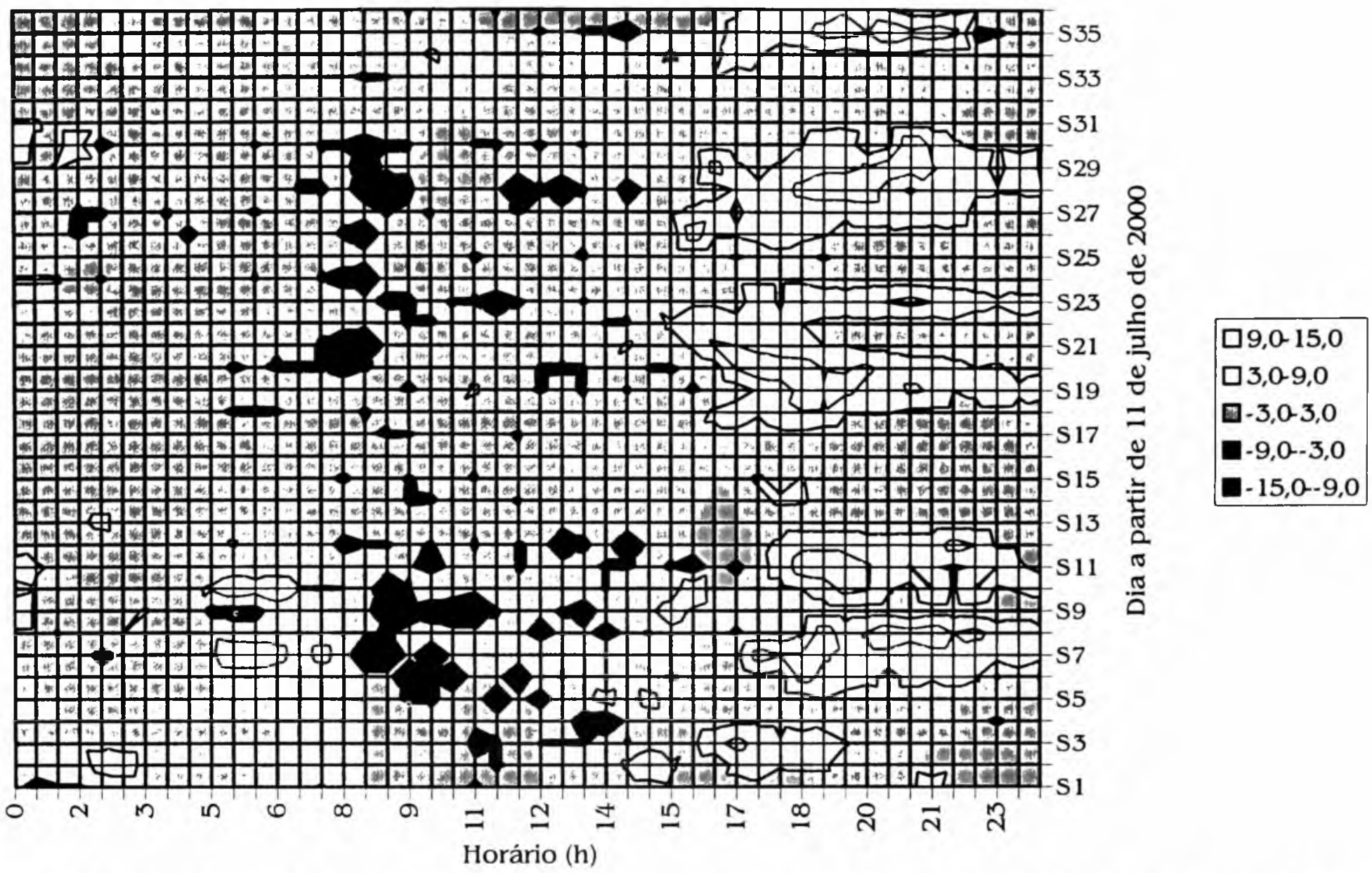

Figura 14: Desvio da umidade relativa do registrador no MMA em relaçāo a do registrador no abrigo padrão (UR1-UR2) (\%).

Notas

1 Ver fotos em AZEVEDO e TARIFA (2001).

2 Marca Onset, Modelo Stow Away XTI02, número de série 223016, pertencente ao acervo do Laboratório de Climatologia e Biogeografia do Departamento de Geografia/USP.

3 Marca Onset, Modelo Stow Away RHO2, número de série 234333, pertencente ao acervo do Laboratório de Climatologia e Biogeografia do Departamento de Geografia/USP.

4 Número de série 233011.
5 Número de série 234322.

6 FUESS, modelo $32 \mathrm{e}$, número de série D-3727.

7 FUESS, modelo 79, número de série $2243 \mathrm{Tr}$.

8 FUESS, modelo $77 \mathrm{~g}$ e número de série $2243 \mathrm{Ur}$.

9 AZEVEDO (2001) sugere que o conceito de instrumento de medida, no caso do registro meteorológico, inclui o abrigo meteorológico e sua periferia imediata já que estes sāo condição si ne qua non do registro meteorológico convencional. 


\section{Bibliografia}

AZEVEDO, T.R. de. Derivação antrópica do clima na Região Metropolitana de São Paulo abordada como função do ritmo semanal das atividades humanas. Tese de Doutorado apresentada à Faculdade de Filosofia, Letras e Cièncias Humanas da Universidade de São Paulo, desenvolvida no Laboratório de Climatologia e Biogeografia sob orientação do Prof. Dr. José Roberto TARIFA. 2001.

AZEVEDO, T.R. de; FUNARI, F.L. Desempenho de registradores digitais de temperatura $e$ umidade do ar em abrigo meteorológico padronizado - estudo comparativo preliminar visando uso em trabalhos de campo. In: Geousp, n.10. Departamento de Geografia da Faculdade de Filosofia, Letras e Ciências Humanas da Universidade de São Paulo. 2001.

AZEVEDO, T.R. de; TARIFA, J.R. O Miniabrigo Meteorológico Aspirado do Laboratório de
Climatologia e Biogeografia e sua aplicação no estudo geográfico do clima. In: Geousp, n. I0. Departamento de Geografia da Faculdade de Filosofia, Letras e Ciências Humanas da Universidade de Sāo Paulo. 2001.

IAG. Observações de Superfície, Efetuadas na Estação Meteorológica. Vol.3, Departamento de Ciências Atmosféricas do Instituto Astronômico e Geofisico da Universidade de São Paulo. 1999.

ONSET. StowAway XTI User's Manual. ONSET Computer Corporation, Bourne, Massachusetts. 1996.

TARIFA, J.R. Sobre um programa de 'climatologia experimental' na Regiāo Metropolitana de são Paulo. In: Boletim Paulista de Geografia, n.52, 1976. Associação dos Geógrafos Brasileiros, São Paulo.

Concluido em: 10/2000 